\title{
Biocatalytic Ketone Reductions using BioBeads
}

\author{
Chew Jia Shen, Ho Thi Thanh Nha and Chi-Lik Ken Lee*
}

Abstract: The increased productivity that can be achieved by performing miniaturized reactions in parallel, without depleting high value reagents, provides the motivation to explore and exploit the current high throughput experimentation technologies. The use of polystyrene beads to coat thin layers of solid reagents offers an elegant strategy to tackle the microscale high throughput solid dispensing conundrum. Herein we report the successful utilization of BioBeads as a first example of high throughput reaction screening with nanomole quantities of ketoreductase on polystyrene beads for asymmetric biocatalytic reactions.

\section{Introduction}

High Throughput Experimentation (HTE) technologies enable vast numbers of biocatalytic reactions to be screened in parallel, this allows the best enzymes and conditions for a desired biotransformation to be determined with high speeds and efficiencies. ${ }^{1}$ Over the past three decades, enzyme engineering has enhanced the stability of wild type enzymes which led to amplifications in catalytic efficiency and stereoselectivity. ${ }^{2-4}$ More importantly, inert non-native substrates are able to undergo the desired biotransformations with enzymes to afford non-native products. $^{3}$ According to Figure 1, large scale manufacturing of $(S)$-Licarbazepine ${ }^{5}$ and Montelukast ${ }^{6}$ provides a glimpse of the efficiencies that can be achieved via engineered ketoreductases (Kred).

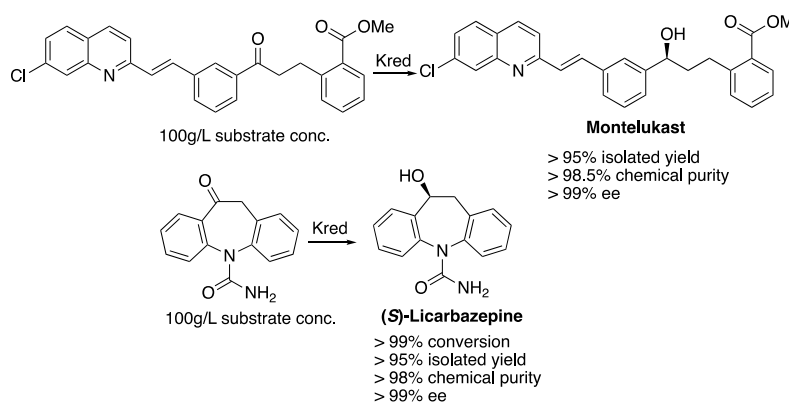

Figure 1. Large scale manufacturing of $(S)$-Licarbazepine and Montelukast via biocatalytic reductions of ketones.

Traditionally, enzyme-based processes were planned based on the limitations of the enzyme. Recent strategies suggested that enzyme variants can be engineered with improved properties to fit the process requirements. These approaches have allowed enzymes to be further engineered with extreme precision to carry out complex molecular processes with higher efficiency. ${ }^{3}$

\footnotetext{
[a] Chew J.S, Ho T.T. N and Dr C-L.K.Lee

Division of Chemistry and Biological Chemistry

School of Physical and Mathematical Sciences, Nanyang Technological

University

21 Nanyang Link, 637371 Singapore.

E-mail: ken.lee@ntu.edu.sg
}

Yet, designing a biocatalyst at a necessary quicker pace remains a daunting challenge since the final enzyme variant normally undergoes $10-20 \%$ alteration compared to its parent wild-type enzyme. ${ }^{7}$ This roughly equates to $10^{390}$ different

permutations of amino acid sequences for a protein that has 300 amino acids.

Truppo described a fourth wave of biocatalysis where biocatalysts are engineered through a rational directed evolution in a design-make-test cycle, combining multidisciplines in this harmonious industrialized work process. ${ }^{7}$ This cycle provided a model of how a protein's function could be impacted via each mutation. While the design phase utilized computation and informatics to generate diverse characteristics of the sequence space to be explored, the make phase exploited biology to afford the necessary enzymes for testing. Finally, the test phase capitalized on HTE to evaluate the performance of each enzyme under the right experimental conditions. ${ }^{7-8}$ Therefore, the role of HTE technologies is paramount to enable more efficient correlations of the enzyme's mutations to its activity, selectivity, expression, proper folding, and stability, amongst other parameters. This leads to a significant reduction in time for each round of protein engineering and thus increasing the performance gain across a variety of metrics. ${ }^{7-11}$

The furtherance and broad impact of high-throughput reaction screening in biocatalysis can be impeded by the scarcity of suitable technologies. ${ }^{12-13}$ Hence it is quintessential to exploit and develop technologies for reaction handling on miniaturized scales to preserve high-value biocatalysts and their co-factors. To this end, glass and polystyrene beads coated with powdered solid reagents have been demonstrated to deliver chemicals with sufficient accuracy on the nanomole scale for HTE. ${ }^{12}$ By employing this universal solid dispensing procedure, we herein report the first successful utilization of BioBeads (polystyrene beads coated with Kred and corresponding co-factors) for the convenient asymmetric biocatalytic reductions of ketones.

\section{Results and Discussion}

\section{Ease of reactions using BioBeads}

Kred reactions (native) are typically carried out in an aqueous buffer with either the nicotinamide adenine dinucleotide phosphate (NADPH) or nicotinamide adenine dinucleotide (NADH) co-factor. This cosubstrate approach has been identified as the most efficient and cost-effective co-factor recycling approach, whereby isopropanol (IPA) is often used as the hydride source for recycling the NADPH cofactor as shown in Scheme $1 .{ }^{13}$ In the standard native Kred reaction approach, NADPH/NADH and the necessary buffer solutions are prepared separately, before Kred and the 
substrate are added. Previous studies have indicated that physical adsorption of powdered enzymes onto non-porous solid supports did not lead to a loss of enzyme activity. ${ }^{14-15}$ However, we did not manage to achieve the desired results when glass beads were used. By adopting a similar "mixed ChemBead" approach by Tu et. al. and the reported random coimmobilization of multienzyme complexes, mixed BioBeads were prepared by coating nanomole quantities of Kred, co-factors ( $\beta-N A D P-\mathrm{Na}_{2}$ and $\beta-\mathrm{NAD}$ $\mathrm{Na}_{2}$; oxidized salts of NADPH/NADH) and buffer reagents onto polystyrene beads. ${ }^{12,13}$ To our delight, the initial test reactions with BioBeads afforded the desired products in relatively high conversion yields. In our standard BioBeads reaction approach, calibrated scoops were used to weigh BioBeads in a volumetric fashion and the subsequent reactions were activated simply by the addition of water, IPA and the carbonyl substrates.

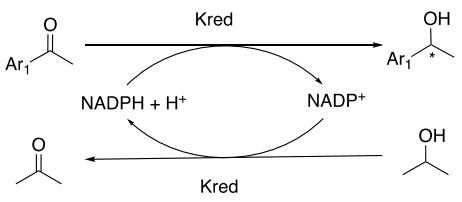

Scheme 1. General co-substrate approach to biocatalytic ketone reduction using isopropanol to recycle NADPH.

\section{BioBeads versus native}

Using acetophenone $\mathbf{1}$ as the general substrate, we sought to unravel and compare the differences between the native and BioBeads reactions. Reactions performed with BioBeads were comparable to the native equivalents such that in most cases, the conversions and enantiomeric excess (ee) were similar.

Table 1. Comparison of BioBeads and native reactions.

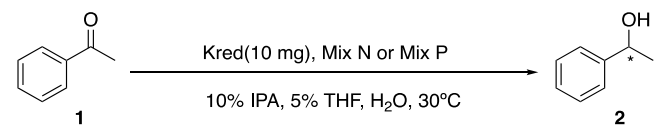

\begin{tabular}{|c|c|c|c|c|c|c|c|}
\hline Entry & Kred & $\mathrm{C}(\%)^{[\mathrm{IT}}$ & $e e(\%)^{\mid{ }^{|l|}}$ & Entry $y^{[a]}$ & Kred & $\mathrm{C}(\%)^{(10)}$ & $e e(\%)^{\mid b^{|l|}}$ \\
\hline 1 & P1-A04 & $>99(91)$ & $>>99(93)$ & 13 & P2-D11 & $98(98)$ & $-1(-22)$ \\
\hline 2 & P1-A12 & $96(91)$ & $>99(69)$ & 14 & P2-D12 & 92(96) & $18(-2)$ \\
\hline 3 & P1-B02 & $98(96)$ & $4(-2)$ & 15 & P2-G03 & $95(95)$ & $77(18)$ \\
\hline 4 & P1-B05 & $98(98)$ & $-6(-2)$ & 16 & P2-H07 & 98(91) & $>999(72)$ \\
\hline 5 & P1-B10 & $98(95)$ & $1(-3)$ & 17 & P3-B03 & 98(96) & $1(-32)$ \\
\hline 6 & P1-B12 & $\begin{array}{l}8(96) \\
\end{array}$ & $33(-3)$ & 18 & P3-G09 & $72(96)$ & $6(-8)$ \\
\hline 7 & P1-C01 & $96(98)$ & $-3(1)$ & 19 & P3-H12 & $96(95)$ & $-15(-45)$ \\
\hline 8 & P1-H08 & $98(96)$ & $-24(-4)$ & 20 & 101 & $\begin{array}{l}9(93) \\
\end{array}$ & $53(25)$ \\
\hline 9 & P2-B02 & $98(98)$ & $-26(-1)$ & 21 & 119 & $94(96)$ & $-99(-99)$ \\
\hline 10 & P2-C02 & $98(97)$ & $-10(-3)$ & 22 & 130 & $93(87)$ & $-99(-92)$ \\
\hline 11 & P2-C11 & $94(98)$ & $41(26)$ & 23 & NADH-101 & $93(97)$ & $25(16)$ \\
\hline 12 & P2-D03 & $98(96)$ & $41(-1)$ & 24 & NADH-110 & $90(94)$ & $93(80)$ \\
\hline
\end{tabular}

Reaction conditions: For entries 1-19, Mix P [128 $\mathrm{mM} \mathrm{Na}_{3} \mathrm{PO}_{4}, 1.7$ $\mathrm{mM} \mathrm{MgSO}_{4}, 1.1 \mathrm{mM} \mathrm{NADP}+$, $\mathrm{pH}$ 7.0. Entries 20-24: identical conditions but using Mix $\mathrm{N}$ [263 $\mathrm{mM} \mathrm{Na}_{3} \mathrm{PO}_{4}, 1.7 \mathrm{mM} \mathrm{MgSO}_{4}, 1.1$ $\mathrm{mM} \mathrm{NADP}{ }^{+}, 1.1 \mathrm{mM} \mathrm{NAD}{ }^{+}, 80 \mathrm{mM}$ D-glucose and $10 \mathrm{Unit} / \mathrm{mL}$ glucose dehydrogenase], $\mathrm{pH} 7.0$. Kred $(10 \mathrm{mg})$, DI water $(0.9 \mathrm{~mL})$, IPA $(0.1 \mathrm{~mL})$, tetrahydrofuran $(0.05 \mathrm{~mL}), 48 \mathrm{hr}$ at $30{ }^{\circ} \mathrm{C}$. ${ }^{[b]}$ Determined by HPLC: numbers inside parentheses represent results from native Kred; numbers outside parentheses represent results with BioBeads; positive and negative \% ee values indicate $R$ and $S$ enantiomers respectively.
Scheme 2 shows the mechanism of $\operatorname{NADP}(H)$ dependent ketoreductases. ${ }^{16-17}$ There are four possible stereochemical transfers of a hydride from the coenzyme, NADPH, to the substrate. The hydride attacks either on the si- or re-face of the carbonyl moiety depending on the orientation of the substrate bound to the enzyme. Based on the type of ketoreductase, either a pro- $(R)$-hydride or pro-(S)-hydride of the $\mathrm{NADPH} / \mathrm{NADH}$ cofactor would be transferred, leading to the formation of the $R$ and $S$ secondary alcohols, respectively. Previous studies demonstrated the various extents to which powdered enzymes can be physically adsorbed onto solid supports. ${ }^{15}$, $18-19$ Under certain conditions the enzymes can even be adsorbed very tightly in the presence of solvents. ${ }^{20}$ Similarly in our BioBeads, we believe that some portions of the macromolecular Kred remain attached onto the polystyrene beads which led to the greater enantioselective discrimination. ${ }^{21}$

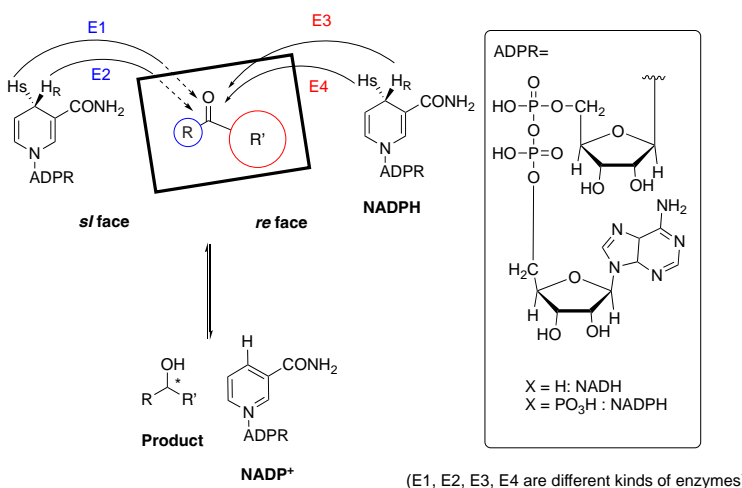

Scheme 2. General ketoreductase carbonyl reduction using IPA for cofactor recycling.

With the successful translation of Kred from its native protocols to BioBeads, we set out to conduct the BioBeads reaction on miniaturized scales. While the recommended quantity of Kred for each reaction was 10 $\mathrm{mg}$, we were able to demonstrate the same reaction on a $0.036 \mathrm{mg}$ scale with BioBeads (Table 2). Similar conversions and enantioselectivities were obtained. Though the percentage errors are evidently higher at lower reaction scales, the reduction of Kred by approximately 278 times revealed the necessary tradeoff in the context of miniaturized reaction screenings. This miniaturized scale was chosen as the most practical scale which also fell within the detection limits of HPLC.

With this miniaturized scale, we extended BioBeads to another substrate 1-(naphthalen-1-yl)ethan-1-one $\mathbf{3}$, akin to the reports by Berglund et. al. on a $2 \mathrm{mg}$ scale. ${ }^{22}$ Gratifyingly, we were able to achieve representative data using much smaller quantities at $0.036 \mathrm{mg}$ of Kred (Table 3). While most entries preserved the \% conversions and enantioselectivities, some entries afforded enhanced figures. 
Table 2. Performance of miniaturized BioBeads reaction

\begin{tabular}{l} 
Kred, Mix N or Mix P \\
\cline { 2 - 7 }
\end{tabular}

Table 3. Comparison of efficiency of BioBeads with 1-(naphthalen1-yl)ethan-1-one as the substrate.

\begin{tabular}{|c|c|c|c|c|c|c|c|}
\hline Entry & Kred & $\mathrm{C}(\%)^{\mid[a]}$ & $e e(\%)^{\text {|a] }}$ & Entry|[a] & Kred & $\frac{\mathrm{C}(\%)^{[\text {[a] }}}{}$ & $e e(\%)^{\sqrt{a \mid}}$ \\
\hline 1 & P1-A04 & $13(14)$ & $-84(-70)$ & 13 & P2-D11 & $90(99)$ & 99(99) \\
\hline 2 & P1-A12 & $3(37)$ & $-2(-14)$ & 14 & P2-D12 & 69(99) & $78(70)$ \\
\hline 3 & P1-B02 & 97(99) & -99(-93) & 15 & P2-G03 & $50(99)$ & $.74(-60)$ \\
\hline 4 & P1-B05 & $30(17)$ & $78(72)$ & 16 & P2-H07 & $33(30)$ & $=70(-72)$ \\
\hline 5 & P1-B10 & $94(99)$ & -99(-90) & 17 & P3-B03 & 95(99) & 99(99) \\
\hline 6 & P1-B12 & $98(99)$ & -99(-90) & 18 & P3-G09 & $8(8)$ & $66(-)$ \\
\hline 7 & P1-C01 & $79(99)$ & $39(80)$ & 19 & P3-H12 & 95(99) & $83(68)$ \\
\hline 8 & P1-H08 & $53(43)$ & $80(80)$ & 20 & 101 & $23(17)$ & -99(-99) \\
\hline 9 & P2-B02 & $79(99)$ & $63(70)$ & 21 & 119 & $31(13)$ & $69(99)$ \\
\hline 10 & P2-C02 & $54(99)$ & $60(51)$ & 22 & 130 & $3(0)$ & $-4(-)$ \\
\hline 11 & P2-C11 & $0(0)$ & $-(-)$ & 23 & NADH-101 & $78(77)$ & $-5(99)$ \\
\hline 12 & P2-D03 & 62(99) & $-80(-45)$ & 24 & NADH -110 & 99(99) & $-98(-99)$ \\
\hline
\end{tabular}
$\left.\mathrm{mM} \mathrm{MgSO}_{4}, 1.1 \mathrm{mM} \mathrm{NADP}{ }^{+}\right], \mathrm{pH} 7.0$. Entries 20-24, identical conditions but using Mix N [263 $\mathrm{mM} \mathrm{Na}_{3} \mathrm{PO}_{4}, 1.7 \mathrm{mM} \mathrm{MgSO}_{4}, 1.1$ $\mathrm{mM} \mathrm{NADP}^{+}, 1.1 \mathrm{mM} \mathrm{NAD}{ }^{+}, 80 \mathrm{mM}$ D-glucose, $10 \mathrm{Unit} / \mathrm{mL}$ Glucose dehydrogenase], $\mathrm{pH}$ 7.0. Kred, DI water $(16.2 \mu \mathrm{L})$, IPA $(3 \mu \mathrm{L})$, dimethyl sulfoxide $(1 \mu \mathrm{L}), 48 \mathrm{hr}$ at $30^{\circ} \mathrm{C}$. ${ }^{[\mathrm{b}]}$ Determined by HPLC: numbers outside parentheses represent results from BioBeads ( $0.036 \mathrm{mg} \mathrm{Kred);} \mathrm{numbers} \mathrm{inside} \mathrm{parentheses} \mathrm{represent} \mathrm{results} \mathrm{by}$ Berglund et al; positive and negative \% ee values indicate $S$ and $R$ enantiomers respectively.

\section{Conclusion}

To conclude, we have successfully provided the first examples of biocatalytic ketoreduction using nanomole quantities of enzyme and co-factors coated onto polystyrene beads. This extension of work from previous reports has shown that negligible variations in the density of polystyrene beads can continue to preclude the need to tediously weigh solids over an analytical balance or to prepare stock solutions, while achieving comparable and in some cases, enhanced conversion yields and enantioselectivities. The demonstration of miniaturized BioBeads reaction array formats can offer the following advantages in HTE and protein engineering: (i) greatly reduces the time and manual labor needed to carry out solid enzyme reagent handling and weighing for large arrays of small-scale reactions; (ii) enables as little as $0.036 \mathrm{mg} \mathrm{Kred}$ to be dispensed for each reaction screening with sufficient accuracy; (iii) allows multiple reagents to be coated onto the same bead for an efficient co-factor recycling; (iv) facilitates wider applicability of polystyrene beads as a screening tool towards other biocatalytic reactions. This method is particularly useful for microscale HTE since it allows for any solid, soluble or not in the reaction solvent, to be dispensed easily at nanomolar quantities.

Keywords: Ketoreductases - Alcohol Dehydrogenases - High Throughput experimentation- Protein Engineering $\bullet$ Reaction Miniaturization

\section{Acknowledgements}

This research was supported by the Ministry of Education (MOE) AcRF Tier 1 funding (Grant Number 2019-T1-002-114) and Nanyang Technological University (startup grant). Chew Jia Shen is grateful to Agency For Science Technology and Research $\left(A^{\star} S T A R\right)$ for an undergraduate scholarship.

\section{References}

[1] Mennen, S. M.; Alhambra, C.; Allen, C. L.; Barberis, M.; Berritt, S.; Brandt, T. A.; Campbell, A. D.; Castañón, J.; Cherney, A. H.; Christensen, M.; Damon, D. B.; Eugenio de Diego, J.; García-Cerrada, S.; García-Losada, P.; Haro, R.; Janey, J.; Leitch, D. C.; Li, L.; Liu, F.; Lobben, P. C.; MacMillan, D. W. C.; Magano, J.; McInturff, E.; Monfette, S.; Post, R. J.; Schultz, D.; Sitter, B. J.; Stevens, J. M.; Strambeanu, I. I.; Twilton, J.; Wang, K.; Zajac, M. A., Org Process Res Dev 2019, 23 (6), 12131242.

[2] Lalonde, J., Curr Opin Biotech 2016, 42, 152158.

[3] Bornscheuer, U. T.; Huisman, G. W.;

Kazlauskas, R. J.; Lutz, S.; Moore, J. C.; Robins, K., Nature 2012, 485, 185-194.

[4] Moody, T. S.; Rozzell, J. D., Chapter 6 - Modern Biocatalytic Ketone Reduction. In Organic Synthesis Using Biocatalysis, Goswami, A.; Stewart, J. D., Eds. Academic Press: 2015; pp 149-185.

[5] Modukuru, N. K.; Sukumaran, J.; Collier, S. J.; Chan, A. S.; Gohel, A.; Huisman, G. W.; Keledjian, R.; Narayanaswamy, K.; Novick, S. J.; Palanivel, S. M.; Smith, D.; Wei, Z.; Wong, B.; Yeo, W. L.; Entwistle, D. A., Org Process Res Dev 2014, 18 (6), 810-815.

[6] Liang, J.; Lalonde, J.; Borup, B.; Mitchell, V.; Mundorff, E.; Trinh, N.; Kochrekar, D. A.; Nair Cherat, R.; Pai, G. G., Org Process Res Dev 2010, 14 (1), 193-198. [7] Truppo, M. D., ACS Med. Chem. Lett.2017, 8 (5), 476-480.

[8] Turner, N. J.; Truppo, M. D., Curr Opin Chem Biol 2013, 17, 212-214.

[9] Hughes, D. L., Org Process Res Dev 2018, 22 (9), 1063-1080

[10] Huisman, G. W.; Liang, J.; Krebber, A., Curr Opin Chem Bio. 2010, 14 (2), 122-129.

[11] Bilal, M.; Iqbal, H. M. N.; Guo, S.; Hu, H.; Wang, W.; Zhang, X., Int.J.Biol.Macromol. 2018, 108, 893-901. 
[12] Martin, M. C.; Goshu, G. M.; Hartnell, J. R.;

Morris, C. D.; Wang, Y.; Tu, N. P., Org Process Res Dev 2019, 23 (9), 1900-1907.

[13] Tu, N. P.; Dombrowski, A. W.; Goshu, G. M.; Vasudevan, A.; Djuric, S. W.; Wang, Y., Angew. Chem. 2019, 58 (24), 7987-7991.

[14] Nagayama, K.; Spiess, A. C.; Büchs, J.,

Biochem. Eng. J. 2010, 52 (2), 301-303.

[15] Nagayama, K.; Spiess, A. C.; Buchs, J.,

Biotechnol. J. 2010, 5 (5), 520-525.

[16] Matsuda, T.; Yamanaka, R.; Nakamura, K.,

Tetrahedron: Asymmetry 2009, 20 (5), 513-557.

[17] De Wildeman, S. M. A.; Sonke, T.; Schoemaker,

H. E.; May, O., Acc. Chem. Res 2007, 40 (12), 1260-1266.

[18] Trivedi, A.; Heinemann, M.; Spiess, A. C.;

Daussmann, T.; Büchs, J., J. Biosci. Bioeng 2005, 99 (4),

340-347.

[19] Ferloni, C.; Heinemann, M.; Hummel, W.;

Daussmann, T.; Büchs, J., Biotechnol. Prog. 2004, 20 (3), 975-978.

[20] Schöpp, W.; Grunow, M., Appl. Microbiol.

Biotechnol. 1986, 24 (4), 271-276.

[21] Cantone, S.; Ferrario, V.; Corici, L.; Ebert, C.;

Fattor, D.; Spizzo, P.; Gardossi, L., Chem. Soc. Rev.

2013, 42 (15), 6262-6276.

[22] Marx, L.; Rios-Lombardia, N.; Farnberger, J. F.;

Kroutil, W.; Benitez-Mateos, A. I.; Lopez-Gallego, F.;

Moris, F.; Gonzalez-Sabin, J.; Berglund, P., Adv Synth

Catal 2018, 360 (11), 2157-2165. 